\title{
Respiratory patterns and risk of sudden unexpected death in infancy
}

\author{
C I FRANKS, J B G WATSON, B H BROWN, AND E F FOSTER \\ Department of Medical Physics, Sheffield University and Area Health Authority (Teaching), and \\ Department of Paediatrics, Sheffield University
}

SUMMARY The overnight respiratory patterns of 25 infants at high risk and 42 infants at low risk of sudden unexpected death were studied during the first 6 months of life. 'Risk' was determined using the birth scoring criteria of Carpenter and Emery. Recordings were made at home using a twinchannel radar chest movement detector which was designed to avoid the need for contact with the infant. The recordings were analysed for respiratory frequency, total duration of apnoea, periodic breathing, duration of regular breathing, and amount of body movement. The high risk group of infants showed respiratory frequencies that were significantly higher than those of the low risk group. None of the other parameters showed significant differences between the groups. These findings do not support the widespread use of home apnoea monitors for infants.

The causes of the 'sudden infant death syndrome' or 'cot death' remain as much a subject for discussion as when the syndrome was defined. Many possible causes have been suggested and it is unlikely that there exists any single primary cause. Indeed it has been noted 'that sudden unexpected deaths at home are a "mixed bag" ', 1 and the possible causes include respiratory infections, ${ }^{2}$ and hypersensitivity to cows' milk protein. ${ }^{3}$

Considerable effort has been made to define procedures for predicting infants at increased risk of sudden unexpected death (referred to as high risk infants in this paper). Carpenter and Emery ${ }^{4-5}$ developed a scoring technique based on parameters available at birth (mother's age, blood group, and incidence of urinary tract infection; duration of second stage labour; birthweight; twin; determination to breast feed). Using these parameters a 'high risk' group could be predicted if the incidence of sudden unexpected death was more than 6 times that of the 'low risk' group - that is the remainder. More recently ${ }^{6}$ the use of factors determined at one month of age enabled the risk group to be defined more precisely. It must be stressed that these scoring procedures refer to sudden unexpected death and not just to those deaths which prove 'unexplainable', the latter often being taken as true 'cot deaths'.

Other procedures for predicting high risk infants have been suggested. Steinschneider ${ }^{7-8}$ found that certain infants showing large amounts of apnoea were at high risk. Southall et al. ${ }^{9}$ have suggested that the incidence of cardiac arrhythmias after birth might provide an indication of high risk. Harper et al. ${ }^{10}$ found differences in heart rates between normal and high risk infants, and Hoppenbrouwers et al. ${ }^{11}$ found differences in respiration rates between such groups.

The work described in this paper was intended to determine if any factors in the respiration pattern of infants are particularly associated with high risk infants if the scoring criteria of Carpenter and Emery are used.4-5 The monitoring equipment was specifically restricted to a system which could readily be used at home. For both this study and previous ones ${ }^{12}$ it was necessary to define parameters suitable for quantitation and to define normal ranges for each.

\section{Method}

Subjects. Studies were made on a total of 67 infants selected randomly from two groups: those scoring as high risk and those scoring as low risk of sudden unexpected death. ${ }^{4-5} 25$ infants were rated as high risk and 42 infants as low risk. The scores were not revealed until after analysis of the respiration data. Birth details of the two groups are given in Table 1. All parents gave informed consent to the study.

Monitor. A portable twin-channel microwave movement sensor ${ }^{13}$ was used to monitor chest wall movements of the infants during sleep. This monitor had been developed specifically because it did not 
Table 1 Birth details of the two groups of infants

\begin{tabular}{|c|c|c|}
\hline & \multicolumn{2}{|l|}{ Infants } \\
\hline & $\begin{array}{l}\text { Low risk } \\
(n=42)\end{array}$ & $\begin{array}{l}\text { High risk } \\
(n=25)\end{array}$ \\
\hline \multicolumn{3}{|l|}{ Birthweight (g) } \\
\hline Mean & 3442 & 3130 \\
\hline Standard deviation & 409 & 519 \\
\hline Range & $2670-4900$ & $2000-3960$ \\
\hline \multicolumn{3}{|l|}{ Delivery } \\
\hline Normal & 24 & 21 \\
\hline Forceps & 9 & 1 \\
\hline Caesarean & 5 & 0 \\
\hline Breech & 4 & 3 \\
\hline Intention to breast feed ${ }^{*}$ & 39 & 7 \\
\hline \multicolumn{3}{|l|}{ Breast fed for at least 4 weeks } \\
\hline after birth & 26 & 7 \\
\hline \multicolumn{3}{|l|}{ Gestational age } \\
\hline$<32$ weeks & 0 & 0 \\
\hline 32-37 weeks & 3 & 4 \\
\hline$>37$ weeks & 39 & 21 \\
\hline
\end{tabular}

*Mother's intention within 48 hours of birth.

need any contact to be made with the infant. Recordings were made using Microlog cassette recorders (Oxford Instruments Ltd) and compensation for speed variation of these recorders was provided. The whole system was battery powered.

Monitoring procedures. Recordings were made during the whole of the overnight sleep periods. Repeat recordings were made at approximately monthly intervals up to 6 months of age. A full set of recordings was not obtained from all infants and the numbers of recordings are shown in Table 2. Parents were encouraged to go about their normal feeding and handling routine while the recording was in progress.
Analysis. Quantitation of the analysis factors was based on the whole overnight recording, excluding periods when the infant was being fed or when there was gross body movement. Analysis was carried out by a combination of computer techniques and manual categorisation from chart paper replays.

Parameters defined. The following parameters were defined for quantitation purposes. These have been described in detail ${ }^{12}$ and the reasons for their choice discussed.

\section{Overall averaged respiratory frequency}

This was calculated (by computer) from the median values of respiratory period (time interval between breaths) for all of the 3-minute epochs in the recording. (The use of median values for epochs reduces the effect on the final result of occasional undetected artefact or long apnoeic episodes.) Calculation was inhibited during periods of movement.

\section{Averaged respiratory frequency during regular} breathing

This was defined in a manner similar to the first parameter (above), except that analysis was only made during regular breathing. Since by definition there is little movement during regular breathing, this parameter should be less affected by artefact and hence should provide a value more suitable for making comparisons with other studies.

\section{Regular breathing}

Regular breathing was taken as any period during which the respiratory frequency was stable and there

Table 2 Results of the analysis of respiratory parameters for the two groups of infants, subdivided into 5-week age intervals

\begin{tabular}{|c|c|c|c|c|c|c|c|c|c|c|c|}
\hline \multirow[t]{2}{*}{ Parameters } & \multirow[t]{2}{*}{$\begin{array}{l}\text { Risk } \\
\text { group }\end{array}$} & \multicolumn{2}{|c|}{$\begin{array}{l}\text { Age } \\
\text { 0-5 weeks }\end{array}$} & \multicolumn{2}{|c|}{ 6-10 weeks } & \multicolumn{2}{|c|}{ 11-15 weeks } & \multicolumn{2}{|c|}{ 16-20 weeks } & \multicolumn{2}{|c|}{ 21-25 weeks } \\
\hline & & Mean & Range & Mean & Range & Mean & Range & Mean & Range & Mean & Range \\
\hline \multicolumn{12}{|l|}{ Respiratory frequency (breaths/min) } \\
\hline Overall & $\begin{array}{l}\text { Low } \\
\text { High }\end{array}$ & $\begin{array}{l}38 \cdot 1 \\
40 \cdot 7\end{array}$ & $\begin{array}{l}28-48 \\
28-57\end{array}$ & $\begin{array}{l}32 \cdot 2 \\
32 \cdot 3\end{array}$ & $\begin{array}{l}22-43 \\
21-40\end{array}$ & $\begin{array}{r}29 \cdot 4 \\
* * 32 \cdot 7\end{array}$ & $\begin{array}{l}23-39 \\
26-40\end{array}$ & $\begin{array}{r}27 \cdot 0 \\
* * 30 \cdot 7\end{array}$ & $\begin{array}{r}21-35 \\
24-39\end{array}$ & $\begin{array}{r}25 \cdot 8 \\
* * 29 \cdot 3\end{array}$ & $\begin{array}{l}18-33 \\
21-37\end{array}$ \\
\hline During regular breathing & $\begin{array}{l}\text { Low } \\
\text { High }\end{array}$ & $\begin{array}{r}36.2 \\
* 40.4\end{array}$ & $\begin{array}{l}26-47 \\
27-56\end{array}$ & $\begin{array}{l}30 \cdot 5 \\
31 \cdot 0\end{array}$ & $\begin{array}{l}21-39 \\
20-40\end{array}$ & $\begin{array}{r}27.9 \\
* * 31.6\end{array}$ & $\begin{array}{l}21-39 \\
23-41\end{array}$ & $\begin{array}{r}25 \cdot 5 \\
* * 29 \cdot 4\end{array}$ & $\begin{array}{l}20-36 \\
22-37\end{array}$ & $\begin{array}{r}24 \cdot 8 \\
* * 28 \cdot 2\end{array}$ & $\begin{array}{l}17-32 \\
20-37\end{array}$ \\
\hline Apnoea, total amount (seconds/h) & $\begin{array}{l}\text { Low } \\
\text { High }\end{array}$ & $\begin{array}{l}32 \cdot 2 \\
19 \cdot 7\end{array}$ & $\begin{array}{l}0-270 \\
0-139\end{array}$ & $\begin{array}{r}11.4 \\
9.9\end{array}$ & $\begin{array}{l}0-50 \\
0-59\end{array}$ & $\begin{array}{l}10 \cdot 2 \\
11 \cdot 0\end{array}$ & $\begin{array}{l}0-80 \\
0-58\end{array}$ & $\begin{array}{l}2 \cdot 6 \\
4 \cdot 4\end{array}$ & $\begin{array}{l}0-13 \\
0-19\end{array}$ & $\begin{array}{l}3 \cdot 5 \\
4 \cdot 6\end{array}$ & $\begin{array}{l}0-19 \\
0-17\end{array}$ \\
\hline Movement ( $\%$ of time) & $\begin{array}{l}\text { Low } \\
\text { High }\end{array}$ & $\begin{array}{l}21 \cdot 2 \\
24 \cdot 4\end{array}$ & $\begin{array}{r}9-39 \\
11-50\end{array}$ & $\begin{array}{l}18 \cdot 7 \\
17 \cdot 6\end{array}$ & $\begin{array}{c}11-34 \\
10-30\end{array}$ & $\begin{array}{l}16 \cdot 0 \\
15 \cdot 9\end{array}$ & $\begin{array}{r}10-30 \\
9-28\end{array}$ & $\begin{array}{l}15 \cdot 8 \\
13 \cdot 3\end{array}$ & $\begin{array}{l}8-29 \\
8-21\end{array}$ & $\begin{array}{l}10 \cdot 6 \\
12 \cdot 6\end{array}$ & $\begin{array}{l}5-17 \\
8-23\end{array}$ \\
\hline $\begin{array}{l}\text { Periodic breathing (total number of } \\
\text { cycles } / \mathrm{h} \text { ) }\end{array}$ & $\begin{array}{l}\text { Low } \\
\text { High }\end{array}$ & $\begin{array}{l}1 \cdot 8 \\
0 \cdot 5\end{array}$ & $\begin{array}{l}0-16 \cdot 9 \\
0-4 \cdot 6\end{array}$ & $\begin{array}{l}1 \cdot 0 \\
1 \cdot 7\end{array}$ & $\begin{array}{l}0-7 \cdot 5 \\
0-11 \cdot 2\end{array}$ & $\begin{array}{l}0.6 \\
0.6\end{array}$ & $\begin{array}{l}0-4 \cdot 1 \\
0-4 \cdot 1\end{array}$ & $\begin{array}{l}0 \cdot 1 \\
0 \cdot 5\end{array}$ & $\begin{array}{l}0-0 \cdot 9 \\
0-6 \cdot 2\end{array}$ & $\begin{array}{l}0 \cdot 1 \\
0 \cdot 2\end{array}$ & $\begin{array}{l}0-0.6 \\
0-1 \cdot 6\end{array}$ \\
\hline Regular breathing ( $\%$ of time) & $\begin{array}{l}\text { Low } \\
\text { High }\end{array}$ & $\begin{array}{l}35 \cdot 9 \\
38 \cdot 7\end{array}$ & $\begin{array}{l}13-51 \\
17-51\end{array}$ & $\begin{array}{l}43 \cdot 1 \\
42 \cdot 2\end{array}$ & $\begin{array}{l}24-57 \\
26-55\end{array}$ & $\begin{array}{l}49 \cdot 6 \\
49 \cdot 0\end{array}$ & $\begin{array}{l}39-65 \\
38-66\end{array}$ & $\begin{array}{l}48 \cdot 0 \\
47 \cdot 8\end{array}$ & $\begin{array}{l}39-57 \\
39-64\end{array}$ & $\begin{array}{l}53 \cdot 1 \\
50 \cdot 6\end{array}$ & $\begin{array}{l}34-66 \\
41-60\end{array}$ \\
\hline Number of recordings (with all factors) & $\begin{array}{l}\text { Low } \\
\text { High }\end{array}$ & $\begin{array}{l}35 \\
26\end{array}$ & & $\begin{array}{l}50 \\
31\end{array}$ & & $\begin{array}{c}34 \\
23\end{array}$ & & $\begin{array}{l}26 \\
19\end{array}$ & & $\begin{array}{l}29 \\
21\end{array}$ & \\
\hline
\end{tabular}

*Difference between the two groups is significant at $\mathbf{P}<0.05$, **difference between the two groups is significant at $\mathbf{P}<0.01$. 
was little gross body movement. The chart recordings were scanned manually and the time spent in regular breathing was expressed as a percentage of the analysed recording time. The criteria for regular breathing were the same as those used previously. ${ }^{12}$

\begin{abstract}
Apnoea
Apnoea was defined as a respiratory period equivalent to at least 3 missed breaths based on the median respiratory period for the 3-minute epoch. This definition is less affected by change in average respiratory frequency with age than a fixed time definition for apnoea. Calculation was carried out by computer but all apnoeic incidents were verified manually.
\end{abstract}

\section{Periodic breathing}

Periodic breathing was taken as an occurrence of regular cyclical variations of signal amplitude (Fig. 1). Quantitation was made in terms of the number of cycles of periodic breathing in the recording, counting only occurrences of $\mathbf{3}$ or more consecutive cycles when the rise and fall of respiratory signal amplitude was more than $50 \%$. The chart recordings were scanned manually.

\section{Gross body movement}

The microwave sensor detects any movement within the beam area and so restlessness of the infant appears as distinctive high amplitude traces with gross irregularity and increased high frequency content. Quantitation was based on these criteria and was expressed as a percentage of the total analysed recording time.

\section{Results}

Respiratory frequency, percentage of regular breathing, and percentage of gross movement showed significant variation with age. Before the two groups of infants were compared the results were normalised for age variations, using linear regression, based on all the results obtained for both groups of infants. The effect of normalising also for gestational age was investigated but had no significant effect on comparisons between the two groups. The results for the two groups were compared first by using all

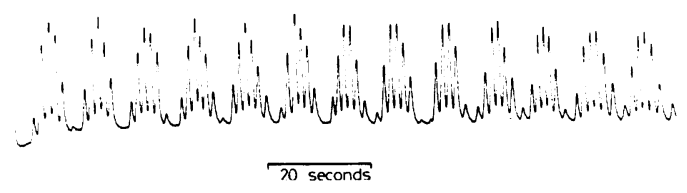

Fig. 1 An example of a long stretch of periodic breathing. individual recordings, and then by taking age normalised average values for all the recordings from a given infant.

The results of the study for the two groups of infants are shown in Table 2.

Average respiratory frequency. Fig. 2 shows how this parameter changes with age. The difference between the two groups is significant: the high risk infants show a higher respiratory frequency than low risk infants $(P<0.001)$. This difference is similar for both the overall average frequency, and the frequency during regular breathing only. From Fig. 2 and Table 2 there is indication of changes with age of the differences between the two groups.

Apnoea. This factor showed a decrease with age but the change was not linear and the distribution of values was not Gaussian (Fig. 3). The two groups were compared using the Mann Whitney U test. There was no significant difference. No apnoeic episode of greater than 15 seconds was detected in any recording.

Periodic breathing. This factor showed a nonGaussian distribution and there was no significant difference between the groups.

Regular breathing and movement. Both factors showed change with age. Neither showed significant difference between the groups (Mann Whitney U test or Student's $t$ test).

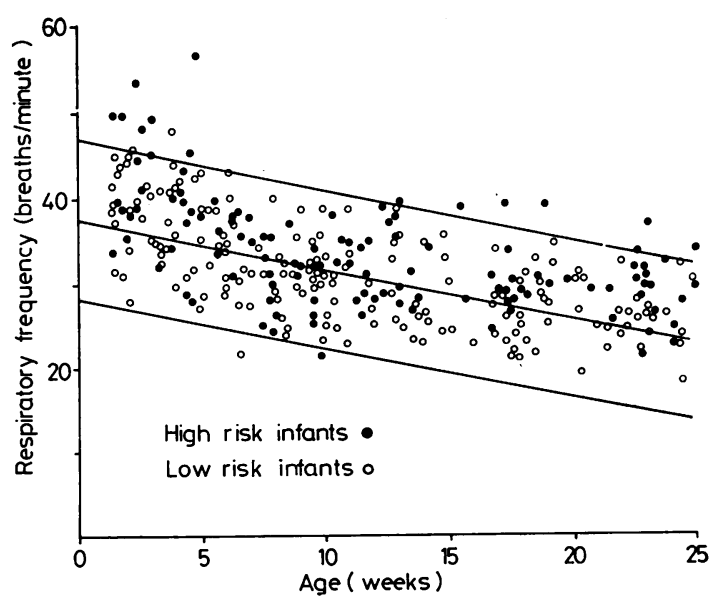

Fig. 2 Change with age of respiratory frequency. The linear regression line and \pm 2 standard deviation lines for the low risk group are also shown. 


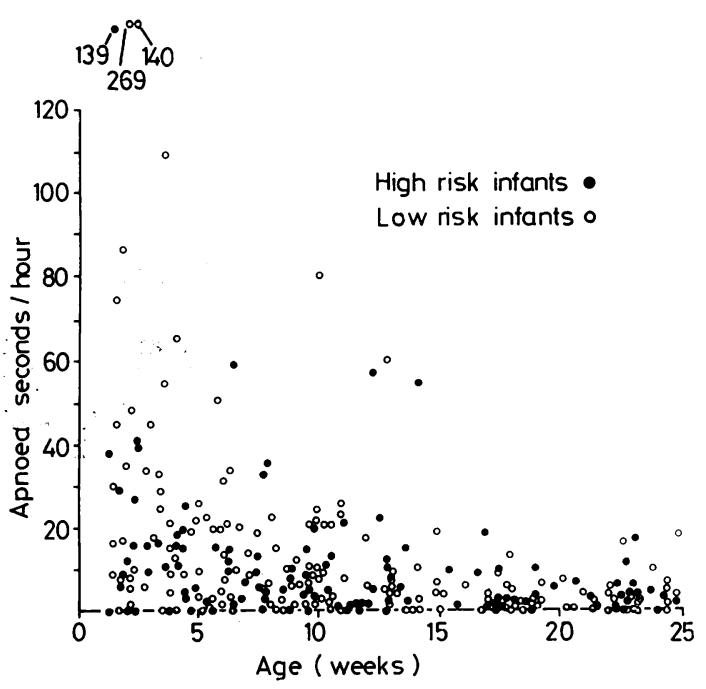

Fig. 3 Change with age of amount of apnoea.

\section{Discussion}

A previous study ${ }^{12}$ showed the value of contactless monitoring of respiratory patterns of infants during sleep in their own homes. Earlier work ${ }^{7}$ suggested that infants at risk from sudden infant death might be identified by demonstrating prolonged apnoeic spells during sleep. Hoppenbrouwers et al. ${ }^{11}$ studied respiratory patterns during sleep in the subsequent siblings of infants who died of sudden infant death and who themselves were at increased risk from sudden infant death syndrome. In that study apnoea density was lower in the study group than in control infants, and the duration of apnoea was shorter. Respiratory rates were consistently higher in the study group than in the control infants during all sleep states. In another study Hoppenbrouwers $e t$ al. ${ }^{\mathbf{1 4}}$ showed that apnoea was common in the normal term infant, but that a sharp reduction in the amount of apnoea occurred between 1 week and 3 months of age. He concluded that apnoea exceeding 15 seconds is rare in infancy and suggests a clinical abnormality.

Although the definition of apnoea used by different workers varies slightly, our finding that the total amount of apnoea is not increased in the high risk group agrees with the findings of the recent studies described above. We did not detect apnoea greater than 15 seconds in any recording. It is possible that our group of infants was too small or that longer periods of apnoea were masked by body movement, and as with all chest movement sensors the monitor could not distinguish upper airways obstruction or disorganised breathing. (We do not know of any respiration monitor suitable for use in homes that truly monitors airflow only and is not affected by body movement.)

The one parameter showing significant difference between the two groups of infants in our study was respiratory frequency, which was higher in the high risk group. This could be because low birthweight was one of the parameters determining high risk, but this was not the only associated parameter. Respiratory frequency was also in part related to the other parameters determining high risk. In particular, feed intention showed almost as significant a relation with respiratory frequency as birthweight (that is intention to breast feed was associated with lower respiratory frequency). This difference in respiratory frequency is also consistent with the findings of Hoppenbrouwers et al. ${ }^{11}$

Interpretation of the findings of our study and those of other workers remains difficult. It would seem that increased respiratory rate should be a factor for consideration when attempting to identify those infants at risk from sudden infant death. Thoman et al. ${ }^{15}$ suggested that respiratory rate and variability should be included, in addition to measurements of apnoea, in the assessment of respiratory characteristics that may place an infant at risk from sudden infant death. Salk et al. ${ }^{16}$ suggested that poorly controlled central mechanisms for maintaining stable cardiac and respiratory function may result in sudden death in infancy.

The work described here underlines the importance, when studying infants thought to be at risk of sudden death, of not restricting respiration monitoring merely to apnoea detection. We feel that any such studies should include an evaluation of variations in respiration rate, although clearly the clinical use of apnoea alarms is a separate issue.

During the course of this study one infant died unexpectedly but was found at necropsy to have evidence of lower respiratory tract infection. This was in fact a high risk infant*. The Carpenter-Emery scoring procedures used in this study ${ }^{4-5}$ refer to sudden unexpected death. A number of infants die unexpectedly and yet have evidence of organic disease demonstrable at necropsy examination. It is possible that a 'physiological' mechanism such as apnoea may be an important factor only in those deaths where there is no clinico-pathological explanation and a study using a scoring procedure which distinguished between 'unexpected' and

\footnotetext{
*The first recording (at $2 \frac{1}{2}$ weeks) on this infant showed a respiratory rate more than 2 standard deviations above the mean for the low risk group. Subsequent recordings and all other factors showed no such differences. Contact with the baby was lost at 13 weeks for social reasons and death occurred at 23 weeks.
} 
'unexplainable' might possibly give more conclusive results. However, there is unlikely to be a clear boundary. For example, Scott et al. ${ }^{2}$ suggested that 'although in some cases of cot death respiratory viruses may be responsible for severe and rapidly overwhelming illness', there is also the possibility 'that minor respiratory illness may trigger sudden apnoea'.

A further important aspect arises from these findings: the increasing use of home apnoea monitors appears to be based on rather limited evidence. While there may be a clinical case for monitoring some infants, wide-scale use of apnoea monitors cannot yet be advocated. We feel that a prospective large study of high risk infants is required including a proper evaluation of the effectiveness of home apnoea monitors.

We thank Professor J L Emery for support, Professor R D Milner and Professor M M Black for encouragement, and Mr S A Pearson and Mrs H Howlett for assistance.

We are grateful for the support of the Trent Regional Health Authority NHS Locally Organised Research scheme through which this work was funded.

\section{References}

1 Anonymous. What kind of cot death? Br Med J 1978; i: $671-2$.

2 Scott D J, Gardner P S, McQuillin J, Stanton A N, Downham M A P S. Respiratory viruses and cot death. Br Med J 1978; ii: 12-3.

3 Parish W E, Barrett A M, Coombs R R A, Gunther M, Camps F E. Hypersensitivity to milk and sudden death in infancy. Lancet 1960; ii: 1106-10.

4 Carpenter R G, Emery J L. Identification and follow-up of infants at risk of sudden death in infancy. Nature 1974; 250: 729.

5 Carpenter R G, Emery J L. Final results of study of infants at risk of sudden death. Nature 1977; 268: 724-5.
- Carpenter R G, Gardner J, McWeeny P M, Emery J L. Multistage scoring system for identifying infants at risk of unexpected death. Arch Dis Child 1977; 52: 606-12.

7 Steinschneider A. Prolonged apnea and the sudden infant death syndrome: clinical and laboratory observations. Pediatrics 1972; 50: 646-54.

8 Steinschneider A. The concept of sleep apnea as related to SIDS. In: Robinson R F, ed. SIDS 1974. Francis E Camps International Symposium on Sudden and Unexpected Deaths in Infancy, Toronto, 1974. Toronto: Canadian Foundation for the Study of Infant Deaths, 1975: 177-89.

- Southall D P, Orrell M J, Talbot J F, et al. Study of cardiac arrhythmias and other forms of conduction abnormality in newborn infants. Br Med J 1977; ii : 597-9.

10 Harper R M, Leake B, Hoppenbrouwers T, Sterman M B, McGinty D J, Hodgman J. Polygraphic studies of normal infants and infants at risk for the sudden infant death syndrome: heart rate and variability as a function of state. Pediatr Res 1978; 12: 778-85.

11 Hoppenbrouwers T T, Hodgman J E, Harper R M, McGinty D J, Sterman M B. Respiratory rates and apnea in infants at high and low risk for sudden infant death syndrome (SIDS) (abstract). Clin Res 1977; 25: 189A.

12 Franks C I, Johnston D M, Brown B H. Non-invasive home monitoring of respiratory patterns in infants. Dev Med Child Neurol 1977; 19: 748-56.

13 Franks C I, Brown B H, Johnston D M. Contactless respiration monitoring of infants. Med Biol Eng 1976; 14: 306-12.

14 Hoppenbrouwers T, Hodgman J E, Harper R M, Hofmann E, Sterman M B, McGinty D J. Polygraphic studies of normal infants during the first six months of life. III. Incidence of apnea and periodic breathing. Pediatrics 1977; 60: 418-25.

15 Thoman E B, Miano V N, Freese M P. The role of respiratory instability in the sudden infant death syndrome. Dev Med Child Neurol 1977; 19: 729-38.

16 Salk L, Grellong B A, Dietrich J. Sudden infant deaths. Normal cardiac habituation and poor autonomic control. $N$ Engl J Med 1974; 291 : 219-22.

Correspondence to Dr C I Franks, Medical Physics Department, Hallamshire Hospital, Glossop Road, Sheffield S10 2JF.

Received 28 August 1979 